\title{
Comparative Study of Mechanical Properties and Thermal Stability on Banyan/Ramie Fiber-Reinforced Hybrid Polymer Composite
}

\author{
T. Raja ${ }^{1 D},{ }^{1}$ S. Ravi, ${ }^{2}$ Alagar Karthick ${ }^{10},{ }^{3}$ Asif Afzal, ${ }^{4,5}$ B. Saleh, ${ }^{6}$ M. Arunkumar $\left(\mathbb{D},{ }^{7}\right.$ \\ Ram Subbiah, ${ }^{8}$ P. Ganeshan $\left(\mathbb{D},{ }^{9}\right.$ and S. Prasath ${ }^{10}{ }^{10}$ \\ ${ }^{1}$ Department of Mechanical Engineering, Vel Tech Rangarajan Dr. Sagunthala R\&D Institute of Science and Technology, \\ Chennai 600062, India \\ ${ }^{2}$ Centre for Materials Research, Chennai Institute of Technology, Chennai 600069, India \\ ${ }^{3}$ Renewable Energy Lab, Department of Electrical and Electronics Engineering, KPR Institute of Engineering and Technology, \\ Coimbatore 641407, Tamil Nadu, India \\ ${ }^{4}$ Department of Mechanical Engineering, P.A. College of Engineering (Affiliated to Visvesvaraya Technological \\ University, Belagavi), Mangalore 574153, Tamil Nadu, India \\ ${ }^{5}$ Department of Mechanical Engineering, School of Technology, Glocal University, Delhi-Yamunotri Marg, SH-57, Mirzapur Pole, \\ Saharanpur, Uttar Pradesh 247121, India \\ ${ }^{6}$ Mechanical Engineering Department, College of Engineering, Taif University, P.O. Box 11099, Taif 21944, Saudi Arabia \\ ${ }^{7}$ Department of Agriculture Engineering, Sri Shakthi Institute of Engineering and Technology, Coimbatore 641062, \\ Tamil Nadu, India \\ ${ }^{8}$ Department of Mechanical Engineering, Gokaraju Rangaraju Institute of Engineering and Technology, Nizampet, \\ Hyderabad 500090, India \\ ${ }^{9}$ Department of Mechanical Engineering, Sethu Institute of Technology, Virudhunagar 626115, Tamil Nadu, India \\ ${ }^{10}$ Department of Mechanical Engineering, College of Engineering and Technology, Mizan Tepi University, \\ Tepi Campus, Tepi 121, Ethiopia
}

Correspondence should be addressed to T. Raja; rajasd28@gmail.com

Received 8 July 2021; Accepted 13 November 2021; Published 17 December 2021

Academic Editor: Pawel Klosowski

Copyright ( 2021 T. Raja et al. This is an open access article distributed under the Creative Commons Attribution License, which permits unrestricted use, distribution, and reproduction in any medium, provided the original work is properly cited.

The usage of natural fibers has increased recently. They are used to replace synthetic fiber products in aircraft and automobile industries. In this study, natural fibers of bidirectional banyan mat and ramie fabrics are used for reinforcement, and the matrix is an epoxy resin to fabricate composite laminates by traditional hand layup technique at atmospheric temperature mode. Five different sequences of reinforcements are as follows to quantify the effect of thermal stability and mechanical behavior of silanetreated and untreated hybrid composites. The results revealed that silane-treated fabric composite laminates were given enhanced mechanical properties of $7 \%$ tensile, $11 \%$ flexural, and $9 \%$ impact strength compared with untreated fabric composite, and at the same time when the increasing of ramie fabric was given the positive influence of $41 \%$ improved tensile strength of $40.7 \mathrm{MPa}, 49 \%$ improved in flexural strength of $38.9 \mathrm{MPa}$ and negative influence in $57 \%$ lower impact strength in sample E and positive value in sample A $21.12 \mathrm{~J}$ impact energy absorbed in the hybrid composite. Thermogravimetric analysis (TGA) revealed the thermal stability of the hybrid composite. In sample A, the thermal stability is more than in other samples, and $410^{\circ} \mathrm{C}$ is required to reduce the mass loss of $25 \%$. The working mass condition of the hybrid composite is up to $3.25 \mathrm{~g}$ after it moves to degrade. 


\section{Introduction}

The expanding interest in ecological cordial materials and the longing to diminish the expense of conventional fiber leads to the improvement of normal fiber composites. Normal fibers are described by indistinguishable parameters and properties from every single fiber and are relied upon to offer equivalent strengthening impacts in a network as their manufactured partners, even though the productivity and level of support might be unique [1]. It is essential to know the reaction of materials under effect stacking to accomplish dependable polymer composite structures. One of the powerless purposes of fiber-strengthened composites is their powerlessness to affect stacking contrasted with metallic structures. The effect prompting harm to structures by outside articles is a test for the creator because of the low effect opposition of the fiberstrengthened composites [2]. It is essential to know the reaction of materials under effect stacking to accomplish dependable polymer composite structures. One of the powerless purposes of fiber-strengthened composites is their powerlessness to affect stacking contrasted with metallic structures. The effect prompting harm to structures by outside articles is a test for the creator because of the low effect opposition of the fiberstrengthened composites [3]. Aramid composites are not as acceptable in compressive quality as glass or carbon composites. Dry aramid fibers are intense and have been utilized as links or ropes and habitually utilized in ballistic applications. Kevlar is maybe the most popular case of aramid fiber. Aramid is the prevalent natural fortifying fiber material for the replacement of steel belting in tires [4]. In a fiber-strengthened polymer, the fibers fill in as support while the assignments of the framework are to hold the strands together, to transmit the shear force, and to function as a covering [5]. The chemical composition also affects the properties of the composite with a percentage of cellulose, hemicellulose, lignin, and waxes. Numerous research work has evidenced the availability, demands, and properties of natural fibers used in polymeric matrices [6].

A successful strategy for improving the effect properties of graphite fiber strengthened composites is to add to them a little level of low modulus high-quality glass strands. Other than improving effect execution, the consolidation of glass strands diminishes the cost, which is confinement for the use of graphite fiber composites [7]. Mechanical testing or structure test is performed to decide the different mechanical properties of materials; there are a few sorts of tests to decide the different mechanical and physical properties of the material. The accuracy aftereffects of these tests are used to decide the practicality of materials for the field application [8]. The capacity to oppose breaking under tractable pressure is one of the most significant and broadly estimated properties of materials utilized in basic applications [9]. The PALF composite revealed that it has low tensile, flexural strength, and high impact strength, and flexural modulus. The hybrid composite offered good tensile and flexural strength by adding KF to $70 \%$ by weight. The PALF raised the impact strength and percentage of energy absorption and flexural modulus of the 3P7K hybrid composite [10]. The advancement on regular fiber hybrid composites was observed for cutting edge applications. Natural fiber, as a substitution of designed fiber, has been one of the most inquired about subjects over the previous years. This is because of its inalienable properties, for example, biodegradability, inexhaustibility, and plentiful accessibility when contrasted with manufactured fibers. Manufactured fibers are obtained from limited assets (nonrenewable energy sources) and are in this way influenced chiefly by instability of oil costs and their gathering in the earth or potential landfill destinations which are their primary disadvantages. Their mechanical properties and thermal properties outperform those of regular strands. A mix of these strands/fillers, as fortification of different polymeric materials, offers new chances to create multifunctional materials and structures for cutting edge applications [11]. This article expects to cover late advancements from 2013-forward-thinking on hybrid composites, because of regular fibers with different fillers. Crossover composites planning and portrayal towards their relevance in cutting edge applications and the present difficulties are likewise displayed. The thermal conduct and dynamic mechanical examination of Pennisetum purpureum/glass-strengthened hybrid composites were explored. Hybrid composite insulation was manufactured utilizing untreated, 5\%, or $10 \%$ alkali-treated Pennisetum purpureum filaments with woven E-glass fibers and epoxy resin [12]. Thermogravimetric (TG) investigation showed that the measure of a build-up of the hybrid composites diminished as the grouping of the alkali used to treat the Pennisetum purpureum filaments expanded. The cracked surface morphology of the examples showed that improved fiber network interfacial holding was accomplished for the 5\% antacid treated Pennisetum purpureum/glass hybrid composites [13].

In this present research, from the above-stated work, natural fibers selected from banyan and ramie fibers are treated with silane solution and without treatment used as reinforcement for the adhesion of epoxy matrix to fabricate five different sequences and analyze the mechanical properties of the treated and untreated hybrid composite, based on the significant results from treated composite laminates to study the thermal stability of mass loss and time taken to degrade the material in silane-treated hybrid composite.

\section{Materials and Methods}

2.1. Materials Overview. Banyan and ramie fiber are the prime materials to fabricate the hybrid composite. Bidirectional banyan mat is supplied by Natural Fabrics, Mumbai, India, and a ramie fabric mat is supplied by Gogreen Products, Chennai, India. The matrix materials of LY556, epoxy resin, hardening HY951, and mold releasing agent of liquid wax were supplied by Javanthi enterprisers, Chennai, India. The physical and chemical properties of the materials used are given in Table $1[14,15]$.

2.2. Fabrication Process of the Hybrid Composite. The research initiates with the collection of natural fibers of banyan and ramie mat. Sequential to the fiber preparation, it is chemically treated with the silane solution of triethoxy(ethyl) silane solution $(\mathrm{pH}=4)$ for $2 \mathrm{hrs}$, and it can be dried $3 \mathrm{hrs}$ at $90^{\circ} \mathrm{C}$ in a hot furnace which is used to improve the mechanical properties of the hybrid composite [16]. The 
TABLE 1: General properties of banyan and ramie fibers.

\begin{tabular}{lccc}
\hline Sl. no. & Details & Banyan fiber & Ramie fiber \\
\hline 1 & Density & $1.92 \mathrm{~g} / \mathrm{cm}^{3}$ & $1.50 \mathrm{~g} / \mathrm{cm}^{3}$ \\
2 & Tensile strength & $51 \mathrm{MPa}$ & $47.7 \mathrm{MPa}$ \\
3 & Young's modulus & $1.5 \mathrm{GPa}$ & $1.3 \mathrm{GPa}$ \\
4 & Cellulose & $16 \%$ & $68.6 \%$ \\
5 & Lignin & $14 \%$ & $0.6 \%$ \\
\hline
\end{tabular}

fabrication process of the hybrid composites was done with the hand layup method. The matrix phase combining Bisphenol-F LY556 epoxy polymer and Araldite HY 951 hardener is used for the better bonding properties of the natural fibers [17]. The comparative study between the samples fabricated with two sets shows that they are treated with silane solution and without fiber treatment to check the mechanical properties, and based on this, thermogravimetric analysis was carried out with an effective set of treated samples of hybrid composite. The motive of the testing of these samples is to verify which weight fraction of the hybrid composition obtained a better result in terms of mechanical and thermal behavior [18]. The weight concentration of banyan/ramie hybrid composite was given in Table 2 .

2.3. Testing of the Hybrid Composite. After the successful fabrication, the material is subjected to mechanical testing and followed by thermal analysis. The strength of the fabricated natural fiber-reinforced composite is tested by tensile, flexural, and impact strength and hardness under loading conditions [19]. The experiments are conducted as per the ASTM standard, as follows: ASTM D638 dimension is $3.2 \mathrm{~mm} \times 13 \mathrm{~mm} \times 165 \mathrm{~mm}$ for tensile strength, ASTM D790 dimension is $3.2 \mathrm{~mm} \times 12.7 \mathrm{~mm} \times 125 \mathrm{~mm}$ for flexural strength, ASTM D 370 dimension is $3.2 \mathrm{~mm} \times 12.7 \mathrm{~mm} \times 64 \mathrm{~mm}$ for impact strength, and their deflections of samples were recorded and categorized for finding the better combination of fiber fraction [20]. Moreover, the thermal stability can be obtained from thermogravimetric analysis with ASTM E1131, and the testing standard was followed for this hybrid composite. Figure 1 shows the testing samples of silane-treated and untreated samples, and Figure 2 shows the experimental setup of tensile testing and SEM analysis equipment. The schematic flow of thermogravimetric analysis is shown in Figure 3.

\section{Results and Discussion}

\subsection{Mechanical Properties of the Hybrid Composite}

3.1.1. Tensile Strength. The tensile strength of ramie/banyan hybrid composite is graphically shown in Figure 4. It is observed that increasing the banyan fiber layer was given higher tensile strength compared to increasing ramie fiber loading. In sample $\mathrm{E}$ was given a maximum tensile strength of $40.7 \mathrm{MPa}$ and $38.06 \mathrm{MPa}$, respectively. The standard deviation was calculated using

$$
s=\sqrt{\frac{1}{N-1} \sum_{i=1}^{N}\left(x_{i}-\bar{x}\right)^{2}} .
$$

In each sample, five different specimens were taken for calculating the better results. The error bar indicates the average value of all the tested samples of hybrid composite. The standard deviation was calculated for five samples in all the experiments: tensile, flexural, and impact strength of the hybrid composite. The standard deviation between five samples for tensile strength is 7.23 for silane-treated samples, and for untreated samples, the standard deviation is 7.69. Similar work was done with natural fibers of kenaf/ grass fibers composite showing the 8.65 standard deviations [20]. Therefore, in silane treatment, the standard deviation was 5\% smaller, with improved tensile strength of the hybrid composite. The maximum tensile strength was obtained for sample E, and the standard deviation calculated with five specimens of sample $\mathrm{E}$ is 0.502 for silane-treated samples and 0.364 for untreated samples. A similar way was followed for other samples of hybrid composite; the tensile test results of epoxy composite laminates are given in Table 3. Therefore, the standard deviation for the silane-treated sample $\mathrm{A}$ is $24 \pm 0.23$ and for the untreated sample is $19 \pm 0.13$.

The major objective of this study is focused on the difference between the chemically treated and untreated reinforcements that can reveal the mechanical properties of ramie/banyan hybrid composite. Therefore, the tensile strength of the hybrid composite clearly shows that the silane-treated fiber mats significantly improved the tensile strength of the hybrid composite [21]. In sample $A$, the maximum difference of $20 \%$ more tensile strength was given due to silane treatment for this hybrid composite, and a minimum of $7 \%$ was achieved in sample E. Therefore, the average difference between treated and untreated fibers in tensile capacity is $13 \%$ more due to silane treatment of fibers before fabrication can give the positive influence between the five different weight fractions of hybrid composite. In another work, banana and neem fibers are reinforced with polymer matrix showing the enhanced tensile strength of $70 \mathrm{MPa}$ due to silane treatment when compared with alkali treatment with $54 \mathrm{MPa}$ and untreated fiber showing $45 \mathrm{MPa}$ of hybrid composite [22]. Therefore, when preparing the hybrid composite, the silane treatment of natural fibers improved the tensile behavior of the hybrid polymer composite.

3.1.2. Flexural Strength. Flexural strengths of treated and untreated ramie/banyan fiber-reinforced hybrid polymer composites with different weight fractions are shown in Figure 5. The flexural strength of the hybrid composite is a major test needed to identify the bending capacity due to this flexural load. In this study, $2 \%$ of the bending capacity can be identified for this hybrid composite by this flexural experiment, and the results revealed that silane-treated samples had improved flexural strength when compared to untreated 
TABLE 2: The weight concentrations of banyan/ramie fiber hybrid epoxy composite.

\begin{tabular}{lcccccc}
\hline Sample & $\begin{array}{c}\text { Epoxy } \\
\text { matrix (g) }\end{array}$ & $\begin{array}{c}\text { Ramie fiber mat } \\
\text { wt. (g) }\end{array}$ & $\begin{array}{c}\text { Banyan fiber mat } \\
\text { wt. (g) }\end{array}$ & $\begin{array}{c}\text { Ramie/banyan } \\
\text { weight fraction }\end{array}$ & $\begin{array}{c}\text { Total composite } \\
\text { wt. (g) }\end{array}$ & $\begin{array}{c}\text { No. of layers present in composite } \\
\text { (banyan/ramie) }\end{array}$ \\
\hline A & 100 & 80 & 20 & $4: 1$ & 200 & $8 \mathrm{~B} / 2 \mathrm{R}$ \\
B & 100 & 60 & 40 & $3: 2$ & 200 & $6 \mathrm{~B} / 4 \mathrm{R}$ \\
C & 100 & 50 & 50 & $1: 1$ & 200 & $5 \mathrm{~B} / 5 \mathrm{R}$ \\
D & 100 & 40 & 60 & $2: 3$ & 200 & $4 \mathrm{~B} / 6 \mathrm{R}$ \\
E & 100 & 20 & 80 & $1: 4$ & 200 & $2 \mathrm{~B} / 8 \mathrm{R}$ \\
\hline
\end{tabular}

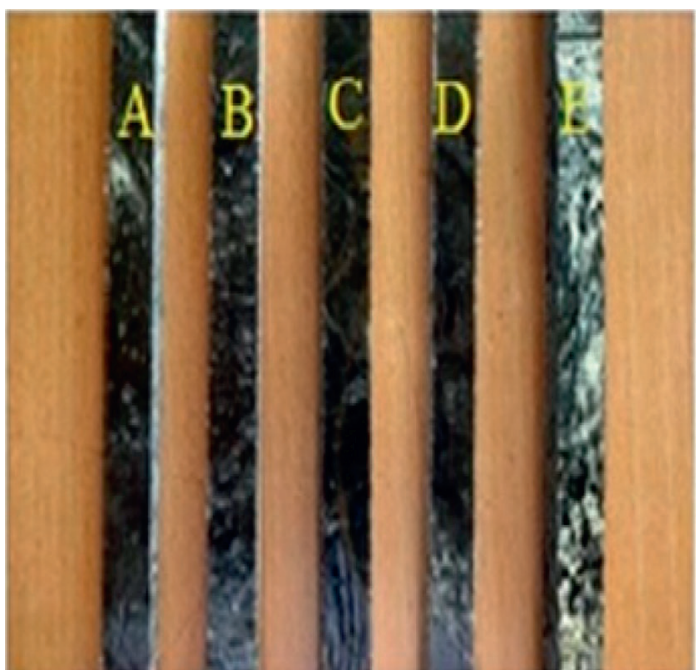

(a)

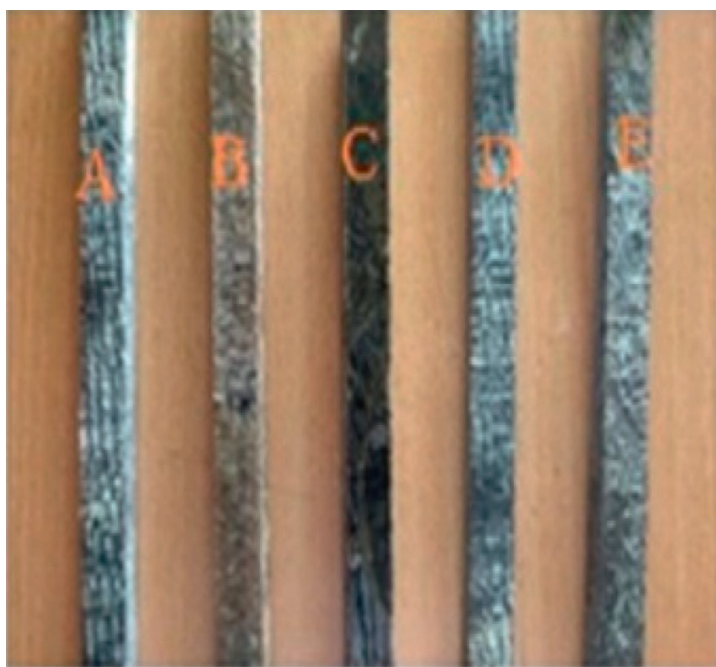

(b)

Figure 1: Tested samples for the flexural test of hybrid composite. (a) Silane-treated samples. (b) Untreated samples.

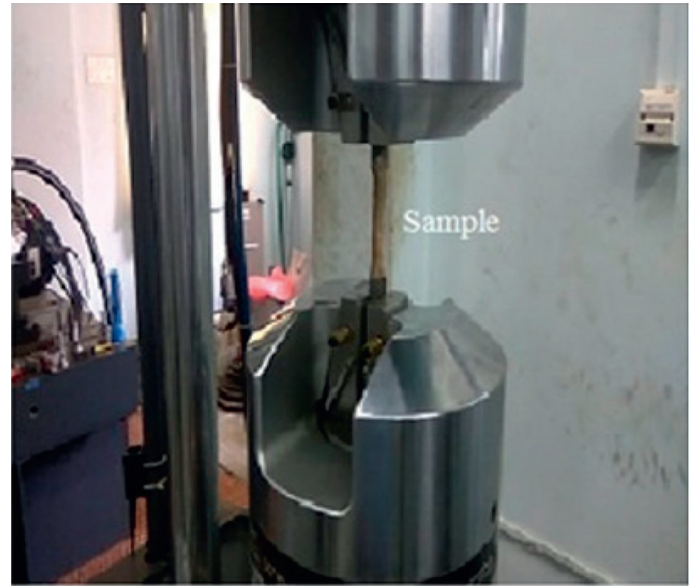

(a)

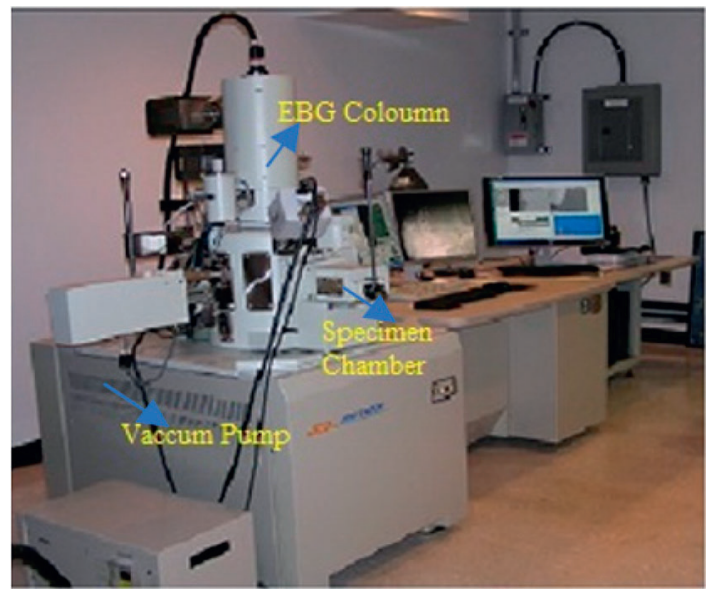

(b)

Figure 2: Experimental setup of (a) tensile test and (b) scanning electron microscopy analysis.

fiber samples [23]. Banyan fiber loading composite sample showed enhanced results when compared to ramie fiber loading composite laminates. The standard deviation of maximum flexural strength for the sample $\mathrm{E}$ with the values of five different specimens was 0.376 for the silane-treated sample and 0.412 for the untreated sample, and the same five different specimens were taken in all the five samples of hybrid composite. Flexural test results of epoxy composite are given in Table 4. Therefore, the standard deviation for silane-treated sample A is $20 \pm 0.14$ and for untreated sample A is $19 \pm 0.11$.

In sample $\mathrm{E}$, the superior flexural strength of hybrid composite was given among all other samples. It clearly shows that increasing banyan fiber loading can withstand 


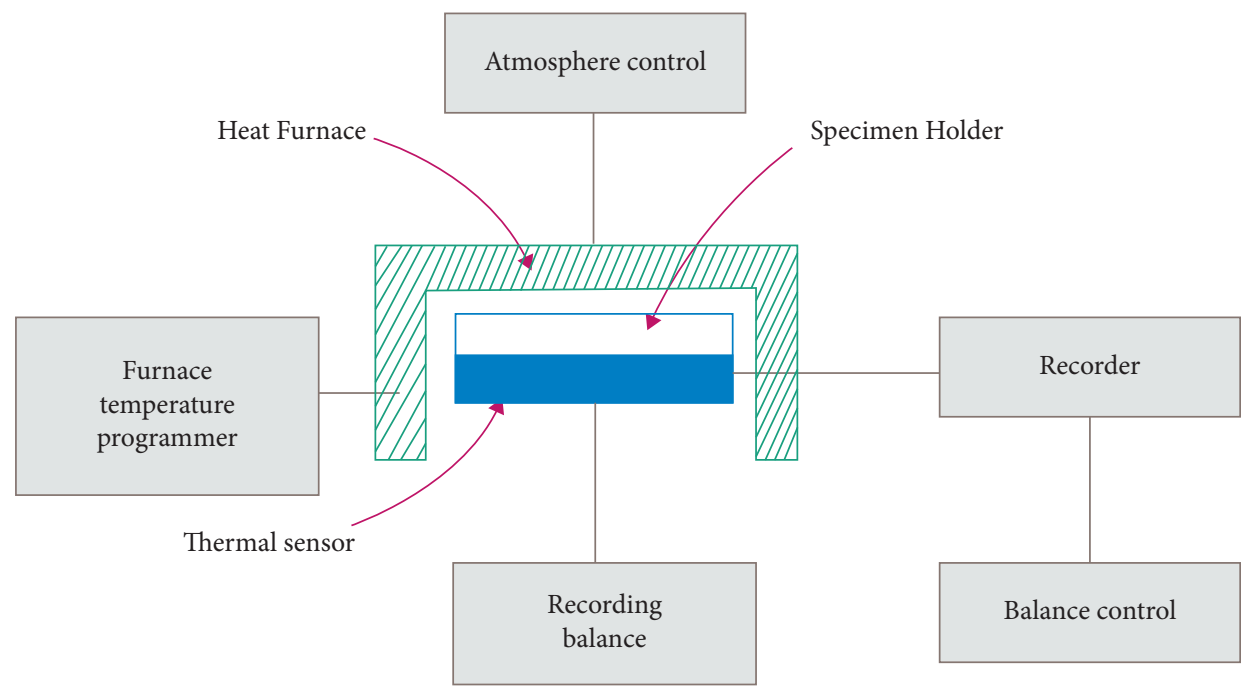

FIGURE 3: Schematic flow of thermogravimetric analysis.

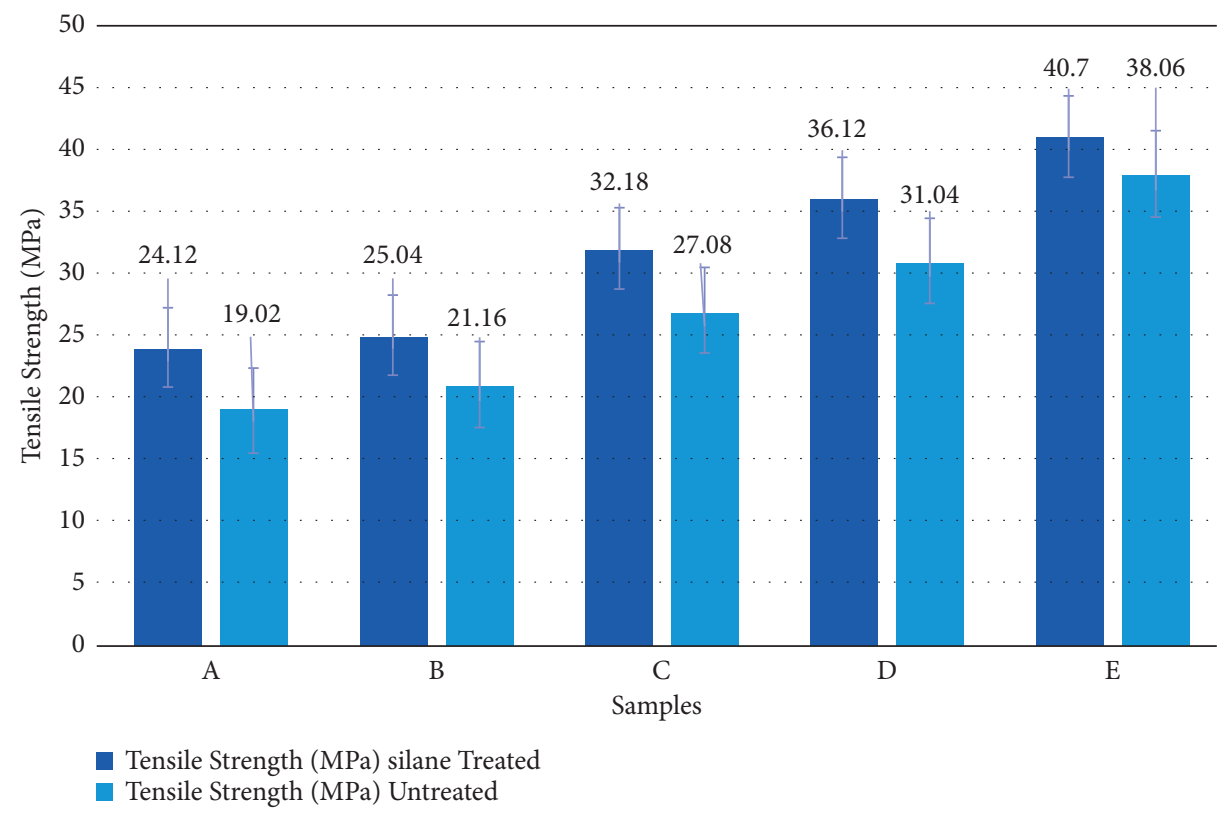

FIgURE 4: Tensile strength of the hybrid epoxy composite.

TABle 3: Tensile test results of an epoxy composite.

\begin{tabular}{|c|c|c|c|c|c|c|c|c|c|c|}
\hline \multirow{2}{*}{ Trials } & \multicolumn{5}{|c|}{ Silane-treated samples } & \multicolumn{5}{|c|}{ Untreated samples } \\
\hline & A & $\mathrm{B}$ & $\mathrm{C}$ & $\mathrm{D}$ & $\mathrm{E}$ & A & $\mathrm{B}$ & $\mathrm{C}$ & $\mathrm{D}$ & $\mathrm{E}$ \\
\hline 1 & 24.0 & 24.9 & 32.2 & 36.4 & 40.5 & 19.2 & 20.9 & 27.6 & 31.2 & 38.5 \\
\hline 2 & 24.1 & 24.8 & 32.2 & 36.1 & 41.0 & 19.1 & 21.2 & 27.1 & 31.0 & 38 \\
\hline 3 & 24.3 & 25.1 & 32.8 & 35.9 & 41.5 & 18.9 & 21.4 & 27.0 & 31.1 & 37.5 \\
\hline 4 & 23.8 & 25.3 & 31.9 & 36.0 & 40.2 & 18.9 & 21.1 & 26.9 & 31.1 & 38.2 \\
\hline 5 & 24.4 & 25.1 & 31.8 & 36.2 & 40.6 & 19.0 & 21.2 & 26.8 & 30.8 & 38.1 \\
\hline Mean & 24.12 & 25.04 & 32.18 & 36.12 & 40.7 & 19.02 & 21.16 & 27.08 & 31.04 & 38.06 \\
\hline Standard deviation & 0.238 & 0.194 & 0.389 & 0.192 & 0.502 & 0.130 & 0.212 & 0.311 & 0.151 & 0.364 \\
\hline
\end{tabular}




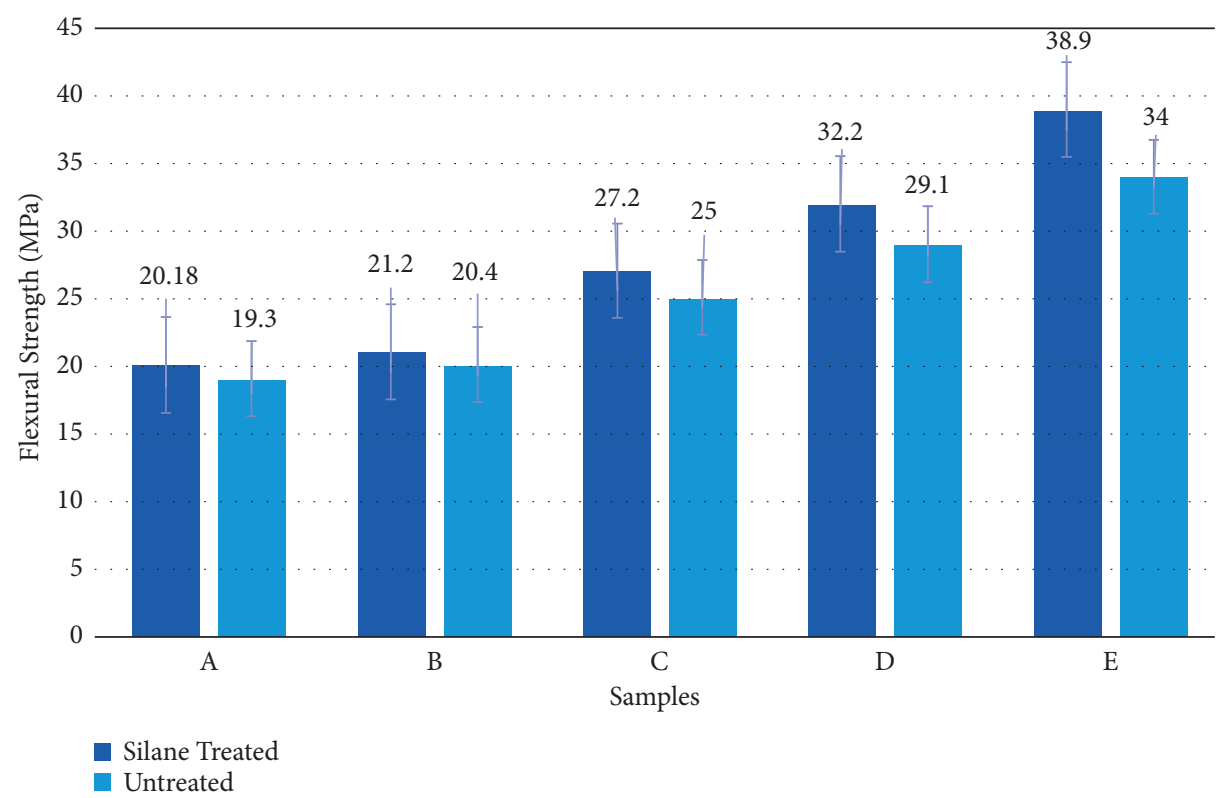

FIgURE 5: Flexural strength of the hybrid epoxy composite.

TABLE 4: Flexural test results of an epoxy composite.

\begin{tabular}{|c|c|c|c|c|c|c|c|c|c|c|}
\hline \multirow{2}{*}{ Trials } & \multicolumn{5}{|c|}{ Silane-treated samples } & \multicolumn{5}{|c|}{ Untreated samples } \\
\hline & $\mathrm{A}$ & $\mathrm{B}$ & $\mathrm{C}$ & $\mathrm{D}$ & $\mathrm{E}$ & $\mathrm{A}$ & $\mathrm{B}$ & $\mathrm{C}$ & $\mathrm{D}$ & $\mathrm{E}$ \\
\hline 1 & 20.1 & 20.9 & 27.3 & 32.1 & 39 & 19.2 & 20.1 & 25.1 & 29.4 & 34 \\
\hline 2 & 20.4 & 20.8 & 271 & 32.4 & 38.5 & 19 & 20.1 & 25.2 & 28.9 & 34.5 \\
\hline 3 & 20.2 & 21.4 & 27.1 & 32.0 & 39.5 & 19.1 & 20.0 & 25.3 & 28.8 & 34.3 \\
\hline 4 & 20.0 & 21.1 & 27.0 & 32.2 & 38.7 & 19.1 & 20.0 & 25.0 & 29.0 & 33.5 \\
\hline 5 & 20.2 & 21.2 & 27.2 & 32.2 & 38.9 & 19.3 & 20.4 & 25.0 & 29.1 & 33.7 \\
\hline Mean & 20.18 & 21.08 & 27.16 & 32.18 & 38.9 & 19.14 & 20.12 & 25.12 & 29.04 & 34.0 \\
\hline Standard deviation & 0.148 & 0.238 & 0.114 & 0.148 & 0.376 & 0.114 & 0.164 & 0.130 & 0.230 & 0.412 \\
\hline
\end{tabular}

more vibration during this bending analysis compared to ramie fiber loading. At the same time, a comparison between treated and untreated fibers can show $4.9 \mathrm{MPa}$ of more flexural strength of the hybrid composite. Similar work was done with different natural fibers of banana and neem also showing that silane treatment of natural fibers can improve the average of $10 \%$ flexural strength of hybrid composite when compared with alkali-treated and untreated fiber composite laminates [24]. Therefore, $12 \%$ superior flexural strength is obtained due to the silane treatment of these natural fibers. In sample A, flexural strengths are 20.18 and 19.3 $\mathrm{MPa}$ revealing $49 \%$ worse results due to the ramie fiber loading with untreated natural fibers. The standard deviation between the silane-treated samples is 7.79 and between the untreated samples is 6.26 . Therefore, the difference between the silane-treated and untreated fibers composite is $1.53 \mathrm{MPa}$.

3.1.3. Impact Strength. Impact strength of ramie/banyan fiber-reinforced composite laminates is shown in Figure 6. The results show that ramie fiber loading has given superior results compared with banyan fiber loading. It is indicated that the physical properties of ramie can give higher impact energy absorption, and silane-treated fiber laminate has given $9 \%$ enhanced impact energy to untreated fibers of hybrid composite laminates. The standard deviation in impact strength analysis for silane-treated hybrid composite is 5.09 and for the untreated fibers composite laminates is 4.82. The standard deviation between the samples is $0.27 \mathrm{~J}$. The better coordination between the fibers and matrix of hybrid composite is revealed. For maximum impact energy, five different specimens were taken for calculating the standard deviation in each sample. For sample A, it is 0.494 in silane-treated mode and 0.439 in the untreated sample of hybrid composite. Impact test results of epoxy composite are given in Table 5. Therefore, the standard deviation of silanetreated sample A is $21 \pm 0.4$.

The comparative study between the silane-treated and untreated results shows the average of $2 \mathrm{~J}$ varies with untreated fiber-reinforced composites from $7.1 \mathrm{~J}$ to $19.16 \mathrm{~J}$ and with silane-treated fiber composites from $9.04 \mathrm{~J}$ to $21.12 \mathrm{~J}$. It can be identified that the superior results from silane-treated laminates are bonded between the fibers and the matrix which are properly blended. However, all samples are having the unique impact energy absorption capacity, but the major 


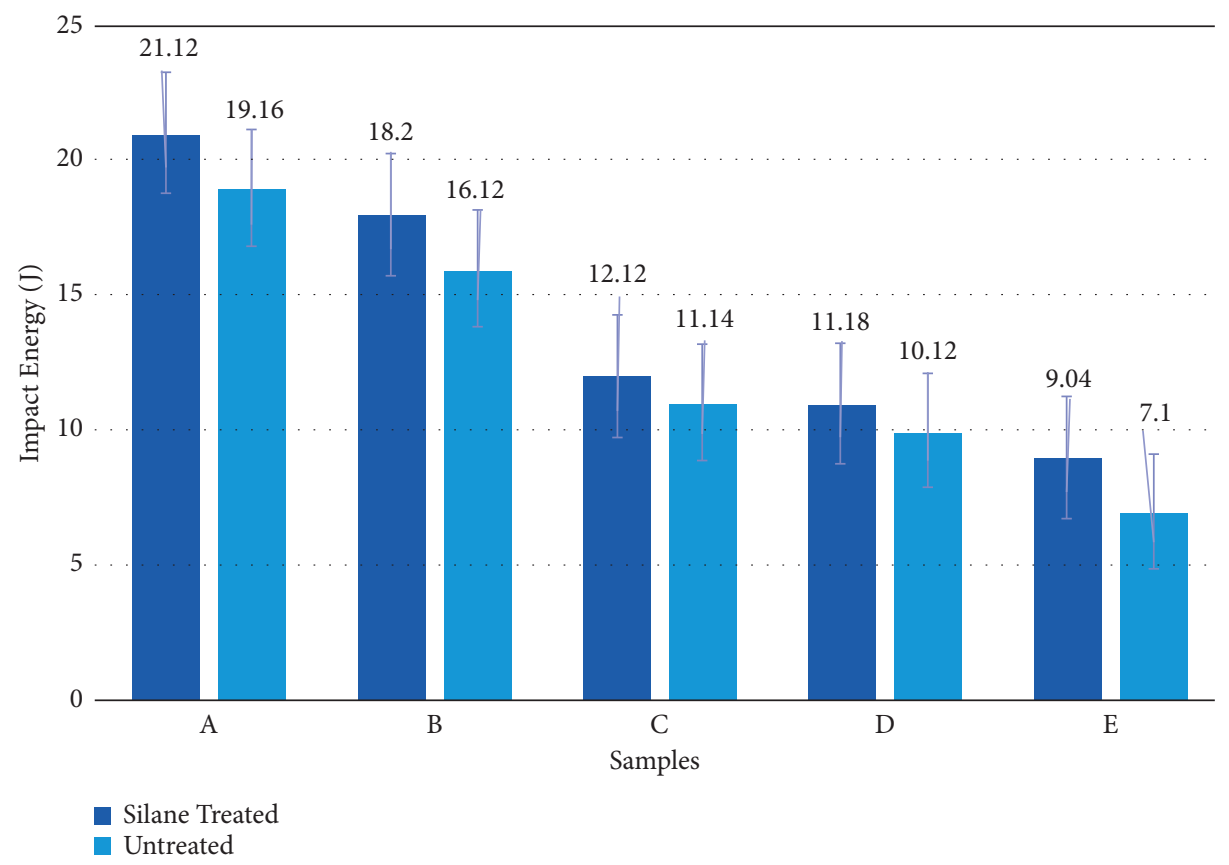

FIgURE 6: Impact strength of the hybrid epoxy composite.

TABLE 5: Impact test results of epoxy composite.

\begin{tabular}{|c|c|c|c|c|c|c|c|c|c|c|}
\hline \multirow{2}{*}{ Trials } & \multicolumn{5}{|c|}{ Silane-treated samples } & \multicolumn{5}{|c|}{ Untreated samples } \\
\hline & A & $\mathrm{B}$ & $\mathrm{C}$ & $\mathrm{D}$ & $\mathrm{E}$ & A & $\mathrm{B}$ & $\mathrm{C}$ & $\mathrm{D}$ & $\mathrm{E}$ \\
\hline 1 & 21 & 18.0 & 12.1 & 11.1 & 9.2 & 19 & 16.2 & 11.0 & 10.4 & 7.1 \\
\hline 2 & 20.5 & 18.0 & 12.4 & 11.3 & 9.1 & 19.5 & 16.1 & 11.0 & 9.8 & 7.3 \\
\hline 3 & 21.5 & 18.1 & 12.0 & 11.2 & 8.9 & 19.2 & 16.0 & 11.2 & 9.9 & 7.1 \\
\hline 4 & 21.7 & 18.3 & 12.0 & 11.1 & 9.0 & 18.5 & 16.0 & 11.4 & 10.2 & 7.0 \\
\hline 5 & 20.8 & 18.6 & 12.1 & 11.2 & 9.0 & 19.6 & 16.3 & 11.1 & 10.3 & 7.0 \\
\hline Mean & 21.1 & 18.2 & 12.12 & 11.18 & 9.04 & 19.16 & 16.12 & 11.14 & 10.12 & 7.1 \\
\hline Standard deviation & 0.494 & 0.254 & 0.164 & 0.083 & 0.114 & 0.439 & 0.130 & 0.167 & 0.258 & 0.122 \\
\hline
\end{tabular}

variation between the banyan fiber loading and ramie loading in sample A is $57 \%$ improved impact strength compared with sample $\mathrm{E}$ in silane-treated mode and $63 \%$ worse impact energy absorption in sample E compared with sample A. Similarly, a hybrid composite of hemp/kenaf fibers reinforced with epoxy matrix in untreated and alkalitreated fibers can show an average of $12 \%$ improved impact strength with chemical treatment [25]. Therefore, the positive influence of this hybrid composite is indicated due to increasing banyan fiber loading compared to ramie fiber loading.

3.2. Morphological Analysis of Treated Hybrid Composites. The fiber pullouts are negligible in the greater weight fraction of ramie fiber-reinforced hybrid composites, as seen in the SEM micrograph of the fractured surface of the hybrid composites. However, as the weight fraction of banyan fibers increases, the fiber pullouts rise as well, owing to the poor adhesion between the banyan fiber and matrix. The SEM image of silane-treated hybrid composite laminates is shown in Figure 7.
3.3. Thermal Stability of the Hybrid Epoxy Composite. Thermal analysis is mandatory for all natural fiber composites [26]. In this research, identifying the thermal stability of silane-treated hybrid composite laminates was selected due to their enhanced mechanical properties when compared to untreated fiber-reinforced composite laminates, and the test was carried out by using thermogravimetric analysis. As per ASTM standard, $13 \mathrm{~g}$ of mass is selected for conducting this thermogravimetric analysis. The mass reduction due to temperature change and time taken for changing the phase of this hybrid composite can be collected from this TGA analysis [27], and the graph is plotted between the percentage of mass reduction and temperature change and the time taken for materials to degrade from its original phase of the hybrid composite, with nitrogen inert gas used as a medium in the furnace of thermogravimetric analysis [28]. The rate of degradation concerning the rate of temperature distribution is at $20^{\circ} \mathrm{C} / \mathrm{min}$ of this hybrid composite [15], and the mass loss percentage selected is $99 \%$, $90 \%, 75 \%, 50 \%$, and $25 \%$ of the mass, and then it will move to decompose [21]. Therefore, up to $25 \%$ mass of this hybrid composite can be utilized with good efficiency. The graph is 

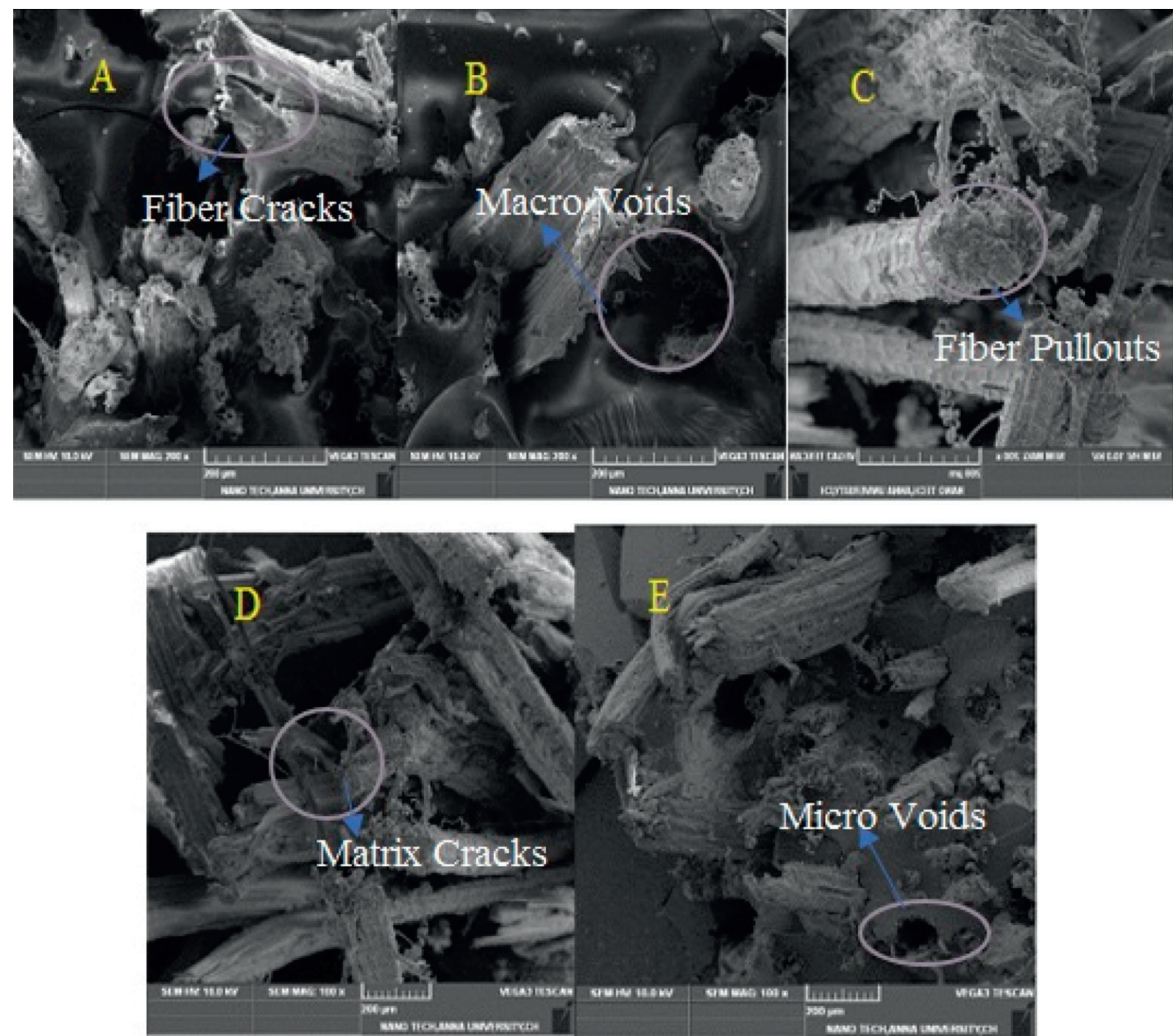

FIGURE 7: SEM micrographs of treated fiber composite laminates.

plotted between the mass loss in terms of percentage and temperature rise as shown in Figure 8.

Thermal stability graphs are revealed when the increasing temperature mass of the hybrid composite is reduced and the thermal stability is more in ramie fiber loading compared to the banyan fiber loading of this hybrid composite. Sample A contains a 4:1 ratio of ramie/banyan fibers which was withstanding a maximum temperature of $410^{\circ} \mathrm{C}$ at $25 \%$ of the mass, and the initial yield temperature of this sample is at $320^{\circ} \mathrm{C}$ at $99 \%$ of the mass. Sample E contains the same ratio with different fibers of banyan/ramie $(4: 1)$ which was withstanding $329^{\circ} \mathrm{C}$ at $25 \%$ of the mass, and the yield temperature is $251^{\circ} \mathrm{C}$ of this hybrid composite. Therefore, the ramie fiber loading can improve the thermal stability by $21 \%$ higher compared with banyan fiber loading during the initial mass reduction from $13 \mathrm{~g}$ to $12.9 \mathrm{~g}$, and the final mass is $3.25 \mathrm{~g}$. In another similar work carried out for natural fibers of neem and banyan, the $25 \%$ mass is taken as final, and then the material will go to decompose, and the thermal stability can maintain to $350^{\circ} \mathrm{C}$ of the hybrid composite [10]. This analysis can identify from the graph that sample A is having higher thermal stability compared with other samples, and it indicates that the ramie fiber has more thermal capacity compared with banyan fiber due to the higher hemicellulose present in this fiber.

Figure 9 shows the graph between the times taken for the composite to degrade concerning mass loss due to temperature rise. The time taken for the decomposition of this hybrid composite can be calculated in all samples, compared with all samples in sample A is taking $16 \mathrm{~min}$ to attain the initial mass 


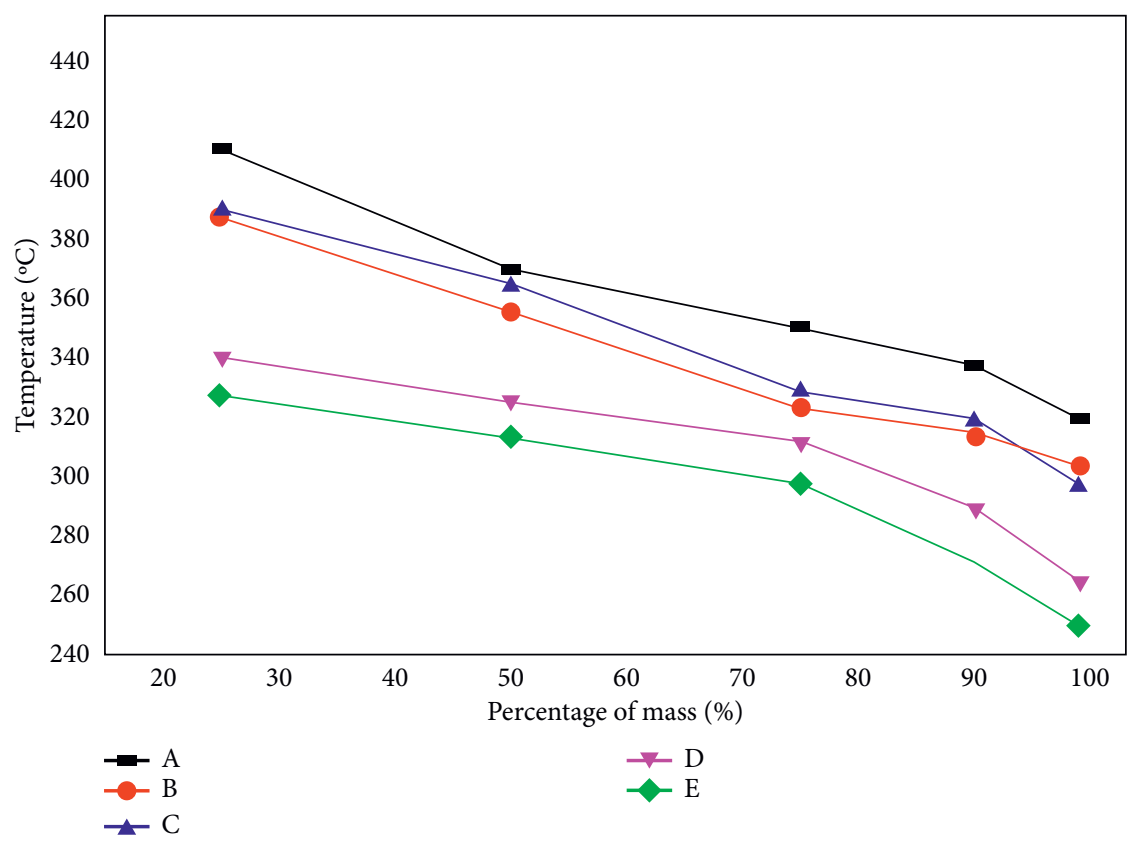

FiguRE 8: The graph between mass loss and temperature of the hybrid composite.

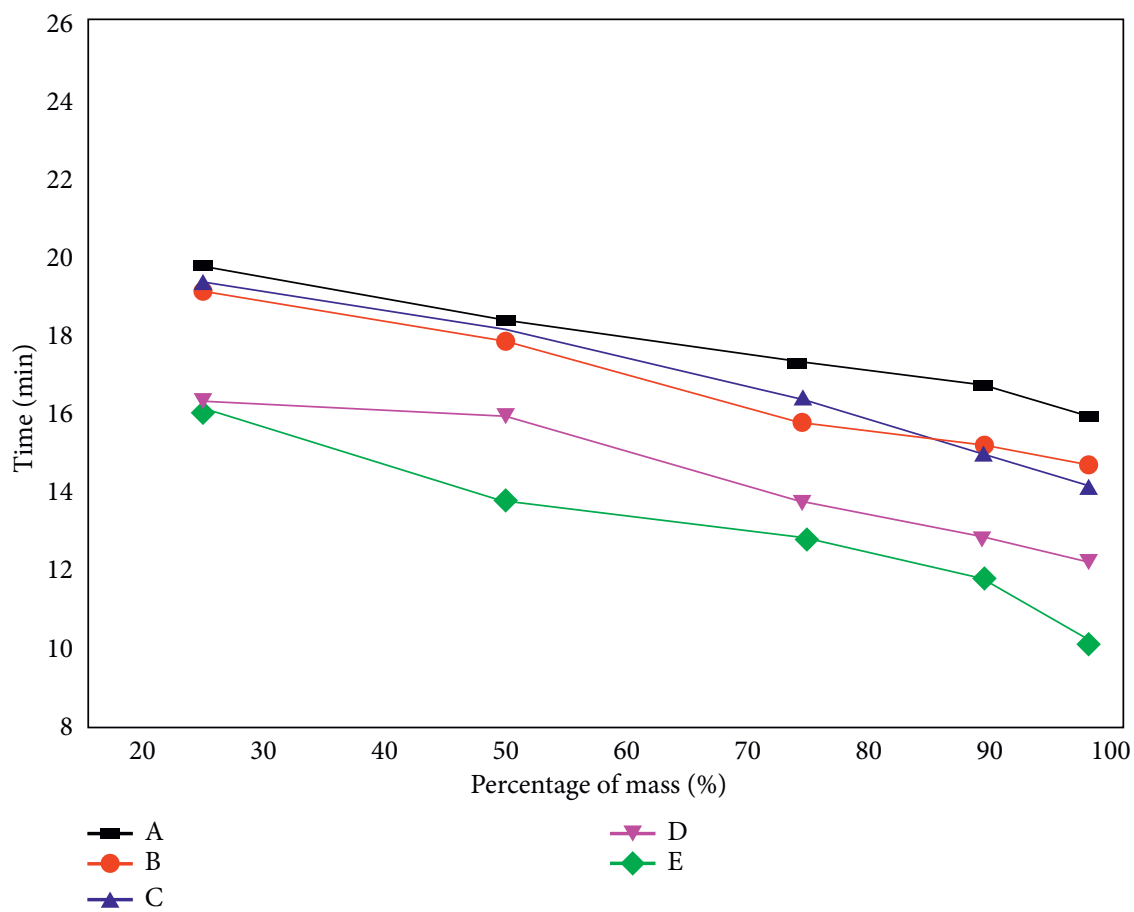

FIgURE 9: The graph between mass loss and time of the hybrid composite.

loss of $12.9 \mathrm{~g}$ and then increasing the temperature that can reflect and reduce the mass up to the working condition of $3.25 \mathrm{~g}$ is taken $20 \mathrm{~min}$ and in other samples are not attain this life of the hybrid composite. Compared with samples A and E, sample A has $36 \%$ more lifetime, and similarly, compared to the sample between $\mathrm{B}$ and $\mathrm{D}$, ramie fiber loading can overcome the banyan fiber loading because the bonding between the fibers with the matrix is high, and sample B has $16 \%$ more lifetime with the fiber ratio of $3: 2$ (ramie/banyan). Therefore, the lifetime of hybrid composite by thermal analysis is more in ramie fiber loading compared with banyan.

\section{Conclusion}

This work revealed the comparative study of the mechanical behavior of silane-treated composites with untreated ramie/banyan fiber hybrid epoxy composite, and 
thermal stability was also carried out to identify the different properties of hybrid composites. The following major observation was carried out in this research:

(i) The major study of this work is a comparison between the treated and untreated natural fiber composite properties, and the result shows clearly that the silane-treated natural fibers can obtain enhanced mechanical properties of tensile, flexural, and impact strength of the hybrid epoxy composite. Based on these superior results present in silanetreated fibers, the composite was selected for conducting thermal analysis by TGA experiments.

(ii) However, the silane treatment can improve the mechanical strength, but the reinforcement of banyan fiber mat is increasing and can give the superior tensile strength of $40.7 \mathrm{MPa}$ and flexural strength of 38.9 MPa. At the same time when the ramie fiber increases, the higher impact strength of $21.12 \mathrm{~J}$ of the hybrid epoxy composite was given.

(iii) Therefore, an average of $12 \%$ improved mechanical properties was obtained due to the initial fiber treatment by silane treatment mode and the reinforcement of both ramie and banyan fibers having good mechanical properties and the bonding of $t$ natural fibers with epoxy polymer matrix that can be suitable for making hybrid composites.

(iv) Thermal stability is more in sample A due to the higher amount of ramie fiber content. Having more cellulose can resist the mass loss during the increasing of temperature and can withstand the maximum of working temperature at $410^{\circ} \mathrm{C}$ in $20 \mathrm{~min}$ and the average of $20 \%$ more lifetime compared with other samples from the thermogravimetric analysis results.

\section{Data Availability}

The data used to support the findings of this study are included within the article.

\section{Disclosure}

The current research work can provide a wide resource of future research extensions to investigate the broad area in hybrid composites. Some of the recommendations towards the future research extension include the following: some of the other properties such as tribological behavior and moisture absorption can be investigated using extensive experiments. The manufacturing of the hybrid fiber composite can be further experimented with extending the addition of other conventional natural fibers and filler materials with various levels of fiber orientation and characteristics.

\section{Conflicts of Interest}

The authors declare that they have no conflicts of interest.

\section{References}

[1] R. Balaji, M. Sasikumar, and A. Elayaperumal, "Thermal, Thermo oxidative and Ablative behavior of cenosphere filled ceramic/phenolic composites," Polymer Degradation and Stability, vol. 114, pp. 125-132, 2015.

[2] E. Chandana and i . Syed Altaf Hussian, "Thermal conductivity characterization of bamboo fiber reinforced in epoxy resin," IOSR Journal of Mechanical and Civil Engineering, vol. 9, no. 6, pp. 07-14, 2013.

[3] P. G. García, R. Ramírez-Aguilar, M. Torres, E. A. FrancoUrquiza, J. May-Crespo, and N. Camacho, "Mechanical and thermal behavior dependence on graphite and oxidized graphite content in polyester composites," Polymer, vol. 153, no. 06, pp. 9-16, 2018.

[4] A. Qadeer Dayo, B.-chang Gao, J. Wang et al., "Natural hemp fiber reinforced polybenzoxazine composites: curing behavior, mechanical and thermal properties," Composites Science and Technology, vol. 144, no. 03, pp. 114-124, 2017.

[5] S. D. Kumar, M. Ravichandran, A. Jeevika, B. Stalin, C. Kailasanathan, and A. Karthick, "Effect of ZrB2 on microstructural, mechanical and corrosion behaviour of aluminium (AA7178) alloy matrix composite prepared by the stir casting route," Ceramics International, vol. 47, no. 9, pp. 12951-12962, 2021.

[6] U. Achutha Kini, M. Shettar, S. Sharma, M. C. G. Pavan Hiremath, H. Anand, and D. Siddhartha, "Effect of hydrothermal aging on the mechanical properties of nanoclay glass fiber epoxy composite and optimization using full factorial design," Materials Research Express, vol. 6, pp. 510-523, 2019.

[7] B. Stalin, M. Ravichandran, G. T. Sudha et al., "Effect of titanium diboride ceramic particles on mechanical and wear behaviour of $\mathrm{Cu}-10 \mathrm{wt} \% \mathrm{~W}$ alloy composites processed by P/M route," Vacuum, vol. 184, Article ID 109895, 2021.

[8] B. Ravichandran and M. Sasikumar, "Mechanical, ablative, and thermal properties of cenosphere-filled ceramic/phenolic composites," Polymer Composites, vol. 37, no. 6, pp. 1906-1913, 2016.

[9] M. Ramesh, K. Palanikumar, and K. H. Reddy, "Plant fibre based bio-composites: s," Renewable and Sustainable Energy Reviews, vol. 79, no. 5, pp. 558-584, 2017.

[10] V. Kavimani, B. Stalin, P. M. Gopal, M. Ravichandran, A. Karthick, and M. Bharani, "Application of r-GO-MMT hybrid nanofillers for improving strength and flame retardancy of epoxy/glass fibre composites," Advances in Polymer Technology, vol. 2021, Article ID 6627743, 9 pages, 2021.

[11] T. G. Yashas Gowda, M. R. Sanjay, K. Subrahmanya Bhat et al., "Polymer matrix-natural fiber composites: an overview," Cogent Engineering, vol. 5, no. 1, 2018.

[12] K. Yorseng, M. R. Sanjay, J. Tengsuthiwat et al., "Information in United States patents on works related to 'natural fibers': 2000-2018," Current Materials Science, vol. 12, no. 1, pp. 4-76, 2019.

[13] S. Mr, S. Siengchin, J. Parameswaranpillai, M. Jawaid, C. I. Pruncu, and A. Khan, "A comprehensive review of techniques for natural fibers as reinforcement in composites: preparation, processing and characterization," Carbohydrate Polymers, vol. 83, no. 11, pp. 108-121, 2018.

[14] K. Bharath, M. Sanjay, M. Jawaid, S. B. Harisha, S. Basavarajappa, and S. Siengchin, "Effect of stacking sequence on properties of coconut leaf sheath/jute/E-glass reinforced phenol formaldehyde hybrid composites," Journal of Industrial Textiles, vol. 49, no. 1, pp. 3-32, 2019. 
[15] S. Abhishek, M. R. Sanjay, G. Raji, S. Siengchin, J. Parameswaranpillai, and C. I. Pruncu, "Development of new hybrid Phoenix, pusilla/carbon/fish bone filler reinforced polymer composites," Journal of the Chinese Advanced Materials Society, vol. 6, no. 5, 2018.

[16] K. Ganesan, C. Kailasanathan, M. R. Sanjay, P. Senthamaraikannan, and S. S. Saravanakumar, "A new assessment on mechanical properties of jute fiber mat with egg shell powder/nanoclay-reinforced polyester matrix composites," Journal of Natural Fibers, vol. 17, no. 4, pp. 480-490, 2018.

[17] P. Kumaran, S. Mohanamurugan, S. Madhu et al., "Investigation on thermo-mechanical characteristics of treated/untreated Portunus sanguinolentus shell powder-based jute fabrics reinforced epoxy composites," Journal of Industrial Textiles, vol. 50, no. 4, pp. 427-459, 2019.

[18] P. Madhu, M. R. Sanjay, P. Senthamaraikannan, S. Pradeep, S. S. Saravanakumar, and B. Yogesha, "A review on synthesis and characterization of commercially available natural fibers: Part-I," Journal of Natural Fibers, vol. 16, no. 8, pp. 1132-1144, 2018.

[19] T. Raja and P. Anand, "Evaluation of thermal stability and thermal properties of neem/banyan reinforced hybrid polymer composite," Materials Performance and Characterisation, vol. 8, pp. 1 481-490, 2019.

[20] K. Mehar, S. K. Panda, and T. R. Mahapatra, "Thermoelastic deflection responses of CNT reinforced sandwich shell structure using finite element method," Scientia Iranica, vol. 25 , pp. 2722-2737, 2017.

[21] S. D. Salman, Z. Leman, M. T. H. Sultan, M. R. Ishak, and F. Cardona, "The effects of orientation on the mechanical and morphological properties of woven kenaf-reinforced poly vinyl butyral film," Bio Resources, vol. 11, no. 1, pp. 1176-1188, 2015.

[22] R. Thandavamoorthy and A. Palanivel, "Testing and evaluation of tensile and impact strength of neem/banyan fiberreinforced hybrid composite," Journal of Testing and Evaluation, vol. 48, no. 1, pp. 647-655, 2020.

[23] M. Jawaid, H. P. S. Abdul Khalil, and O. S. Alattas, "Woven hybrid bio-composites: dynamic mechanical and thermal properties," Compos Part A Appl Sci Manuf, vol. 43, no. 2, pp. 288-293, 2012.

[24] V. J. Binu Kumar, J. Bensam Raj, R. Karuppasamy, and R. Thanigaivelan, "Influence of chemical treatment and moisture absorption on tensile behavior of neem/banana fibers reinforced hybrid composites: an experimental investigation," Journal of Natural Fibers, Article ID 1838995, 12 pages, 2020.

[25] S. Huo, A. Thapa, and C. A. Ulven, "Effect of surface treatments on interfacial properties of flax fiber-reinforced composites," Advanced Composite Materials, vol. 22, no. 2, pp. 109-121, 2013.

[26] D. Hristozov, L. Wroblewski, and P. Sadeghian, "Long-term tensile properties of natural fibre-reinforced polymer composites: comparison of flax and glass fibres," Composites Part B: Engineering, vol. 95, pp. 82-95, 2016.

[27] A. V. Kiruthika, "A review on physico-mechanical properties of bast fibre reinforced polymer composites," Journal of Building Engineering, vol. 9, pp. 91-99, 2017.

[28] L. Yan, N. Chouw, L. Huang, and B. Kasal, "Effect of alkali treatment on microstructure and mechanical properties of coir fibres, coir fibre reinforced-polymer composites and reinforced-cementitious composites," Construction and Building Materials, vol. 112, no. 1, pp. 168-182, 2016. 